\title{
Medical schools continue to tighten noose on faculty with conflicts of interest
}

Published at www.cmaj.ca on Jan. 8

$\mathrm{T}$ he arsenal of tools being used to promote greater disclosure of conflicts of interest by medical faculty continues to expand as the Harvard Medical School in Boston, Massachusetts, has become the first school in the United States to require medical professors to disclose to students all of their financial ties to industry. Meanwhile, the University of Sydney in Australia has created a regime in which a committee, rather than faculty themselves, will determine whether an industry tie constitutes a conflict.

In response to student protests and increasingly harsh criticism, Harvard moved to obligate professors and lecturers to disclose their industry ties to students in class. The school also set up a new committee to review its conflictof-interest policies. And two affiliated research hospitals have restricted the amount of money that several senior staff members who sit on industry boards can earn from pharmaceutical or biotechnology companies.

More than 200 medical students protested the growing influence of industry in their classrooms after a spate of scandals, including a US Senate investigation into accusations that three of the school's professors failed to properly report US\$4.2 million in payments from drug companies from 2000 to 2007.

In 2008, pharmaceutical companies contributed US\$8.6 million to Harvard for basic science research and US $\$ 3$ million for continuing education. Furthermore, 149 members of the medical faculty have disclosed financial ties to Pfizer and 130 have disclosed ties to Merck.

The American Medical Students Association, which gives medical schools ratings based how well they monitor and manage money from the drug industry, recently gave Harvard Medical School an F grade.

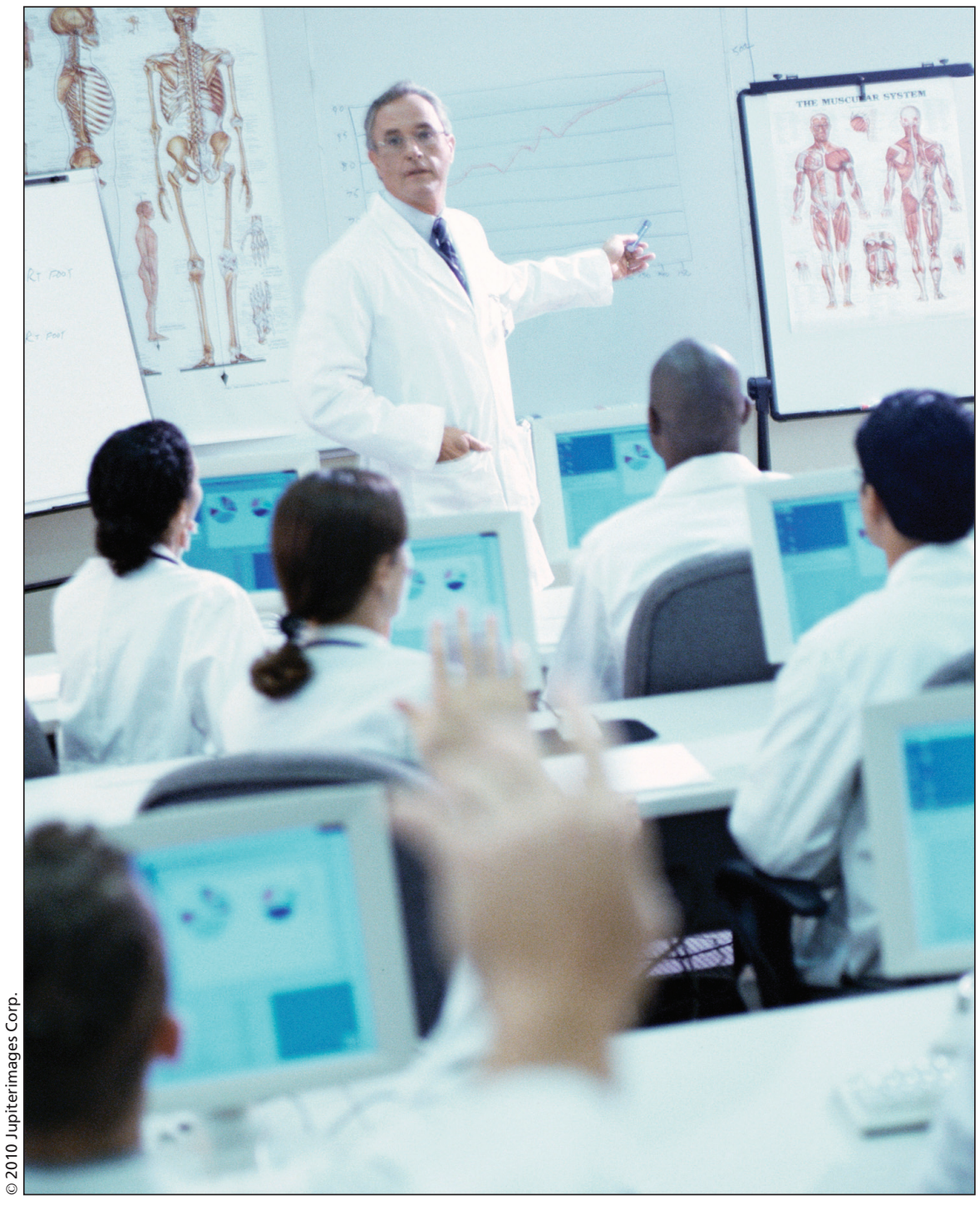

Medical professors and lecturers will be obliged to disclose their industry ties to students before they teach classes at Harvard Medical School in Boston, Massachusetts.

Other medical schools are making efforts to be more transparent in their dealings with industry. For instance, the Feinberg School of Medicine at Northwestern University in Chicago, Illinois, has created online faculty profiles that include the industry relationships of about 2000 staff members.

Across the US, about 35 universities are creating new policies to guide the relationship between academia and industry, according to the American Medical Student Association.

The University of Sydney medical school, meanwhile, adopted a policy requiring staff to disclose all industry ties to a newly established committee that will determine whether the external earnings constitute a conflict of interest. Prior to that, faculty were allowed to make 
their own determination as to whether financial ties to industry caused a conflict.

"We have a university-wide COI [conflict-of-interest] policy that gets very few disclosures in our Sydney medical school when we just asked for COI, so we decided to take a less headon approach and ask for disclosures of external interests," wrote Dr. Ben Freedman, deputy dean of the medical school in an email. "This has brought out a much larger response."

Two faculty disclosures have already been flagged as potential conflicts by the committee, Freedman added.

Student protests, like the one at Harvard, are forcing schools around the world to re-examine their conflict policies, wrote committee chair Dr. Martin Tattersall in an email. "I think the US action in this area has stimulated review in Sydney. I have a medical student undertaking a survey of medical school policies in Australia in a manner similar to that done by the American Medical Students Association."

The moves by Harvard and Sydney follow on the heels of attempts by the Association of American Medical Colleges to enforce a zero-tolerance approach to industry handouts on the part of the nation's teaching hospitals and 129 medical schools (CMAJ 2008. DOI:10.1503/cmaj090780).

Several American universities, including Yale, Stanford, Pennsylvania, Vanderbilt, Pittsburgh and the University of California at Davis, have already adopted partial policies forbidding faculty or residents from accepting cash, gifts or free lunches from industry. But those policies are highly variable and often don't address such issues as faculty participation in industry-sponsored programs, such as speakers bureaus.

Although there's widespread variation in the policies of Canadian medical schools, officials have argued that low levels of abuse mitigate the need for more restrictive policies on pharmaceutical and medical devices industry handouts for medical education (CMAJ 2008. DOI:10.1503/cmaj.081008). But the Association of Faculties of Medicine of Canada and the medical advocacy group, the Canadian Association for Medical Education, are exploring the need for more restrictive guidelines (CMAJ 2008. DOI:10.1503/cmaj .081268). - Andrea Ozretic, Ottawa, Ont., and Roger Collier, CMAJ

DOI:10.1503/cmaj.109-3151 